\title{
"CRIATURAS EXTRAÑAS SOMOS TODOS": METAMORFOSIS, POSTHUMANISMO Y PENSAMIENTO DEL CUERPO EN MOHO DE PAULETTE JONGUITUD ACOSTA
}

\author{
Daniel Zavala Medina \\ Universidad Autónoma de San Luis Potosí \\ daniel.zavala@uaslp.mx
}

Resumen: El objetivo de este artículo es proponer una lectura de la novela breve Moho (2010) de la escritora mexicana Paulette Jonguitud Acosta, a partir de algunas reflexiones sobre la corporalidad que el horizonte posthumanista ha hecho posibles. Si el humanismo postulaba — de manera directa o indirecta - un tipo de cuerpo privilegiado (varón, heterosexual, blanco, europeo, burgués, etc.), desde una perspectiva posthumanista se pone en crisis ese modelo corporal único y predominante. En este sentido, la metamorfosis del cuerpo de Constanza, protagonista de la obra, permite el despliegue de una serie de (y una meditación sobre) otras posibilidades corporales: animal, monstruo, vegetal, etc. Para el análisis, se empleará fundamentalmente la noción de pensamiento del cuerpo postulada por Julieta Yelin.

Palabras clave: Moho, Paulette Jonguitud Acosta, novela corta, posthumanismo, corporalidad

\section{"STRANGE CREATURES WE ARE ALL": METAMORPHOSIS, POST-HUMANISM, AND "THOUGHT OF THE BODY" IN MOHO BY PAULETTE JONGUITUD ACOSTA}

\begin{abstract}
This paper aims to propose a reading of Moho (2010), a short novel by Mexican author Paulette Jonguitud Acosta, starting from some insights on corporeality made possible by the posthumanist horizon. If humanism posited — directly or indirectly - a type of privileged body (male, heterosexual, white, European, bourgeois, etc.), this predominant and single model of the body is challenged from a post-humanist perspective. In this sense, the metamorphosis suffered by the body of Constanza, the protagonist of the novel, allows us to deploy a series of (and a meditation on) other corporeal possibilities - animal, monster, vegetable, etc. For the analysis, Julieta Yelin's notion of "thought of the body" will be applied.
\end{abstract}

Keywords: Moho, Paulette Jonguitud Acosta, short novel, post-humanism, corporeality

\section{DOI: $\underline{\text { https://doi.org/10.24029/lejana.2020.14.908 }}$}

Recibido: el 17 de agosto de 2020

Aceptado: el 22 de octubre de 2020

Publicado: el 26 de febrero de 2021 


\section{Presentación}

Cary Wolf es uno de los intelectuales anglosajones más visibles del posthumanismo. En 2007, fundó la colección "Posthumanities", serie editada por la Universidad de Minnessota. ${ }^{1}$ En "Breve estado de la cuestión animal”, Julieta Yelin explica acerca del nombre de la colección:

se puede entender la "poshumanidad" como un tiempo y un espacio en el que se producen y ponen a prueba un conjunto de conceptos para intentar aprehender los devastadores efectos de la crisis del humanismo como horizonte de pensamiento; no sólo los que tuvo sobre el corpus de la filosofía, sino también sobre los desarrollos de los saberes políticos, estéticos, científicos. O, en otras palabras, como un proceso histórico en el que el descentramiento de lo humano - a causa, fundamentalmente, de los avances tecnocientíficos y del estrepitoso fracaso del capitalismo- es cada vez más difícil de ignorar. Un estado de cosas, en definitiva, en el que el humanismo puede ser percibido como un paradigma históricamente datado y no como nuestro "natural" modo de pensar. (Yelin, 2017: 30)

\section{Por otro lado, Yelin acota que la noción de posthumanismo}

se identificaría con la búsqueda de nuevas prácticas críticas — artísticas e intelectuales-, esto es, formas de diálogo transdisciplinar que no se limiten a compartir perspectivas o métodos, lo cual suele dar resultados bastante empobrecedores, sino que pongan en cuestión los límites que separan un campo de otro, que interroguen, desde la práctica específica, los fundamentos de dicha especificidad. Esta búsqueda, que es connatural al pensamiento poshumanista, se apoya en la hipótesis de que esos límites establecidos a priori suelen estar vinculados, en la mayoría de los casos, a una concepción compartimentada y jerárquica del conocimiento. (Yelin, 2017: 31)

En un contexto con estas características, es muy pertinente la interrogante lanzada por Cragnolini:

¿Será necesario seguir preservando una "propiedad" de lo humano, o las humanidades deberán afrontar este nuevo desafío de pensar en un hombre "desapropiado", con confines difusos, no claros, no fácilmente identificables? Tal vez, la aceptación de esos confines menos claros, permita "otro modo de ser humano" en otro vínculo con la comunidad de lo viviente. Si ser hombre ha significado "ser dueño, señor y propietario" de todo lo demás (lo no humano, pero también otros humanos) tal vez sea el tiempo en que, por la deconstrucción del concepto de hombre y de humanidades, podemos pensar otro modo de ser-en-el-mundo. (Cragnolini, 2014: 14) ${ }^{2}$

La corporalidad es uno de los temas más recurrentes, significativos y problemáticos en la literatura latinoamericana contemporánea. La narrativa mexicana suscribe esa preocupación por y sobre el cuerpo. En particular, las escritoras han mostrado un profundo interés en desarrollar tramas donde la corporalidad es un eje fundamental de sus relatos. Ejemplo de ello son algunos textos de

\footnotetext{
${ }^{1}$ Consúltese su sitio web: https://www.upress.umn.edu/book-division/series/posthumanities.

${ }^{2}$ En el ámbito de América Latina, son muy útiles los materiales sobre animalidad y posthumanismo que se publican en la Revista Latinoamericana de Estudios Críticos Animales. Su número junio-diciembre de 2020, por ejemplo, incluye el dossier "Cartografías (im)posibles en torno a lo posthumano, la crítica de lo humano y el problema de la animalidad" (http://revistaleca.org/journal/index.php/RLECA/issue/view/15).
} 
Daniela Tarazona, Guadalupe Nettel, Paulette Jonguitud Acosta, Cecilia Eudave, Fernanda Melchor, Nadia Villafuerte, Atenea Cruz, Patricia Laurent Kullick, entre otras. Varias de esas obras comparten algunas características en común: por un lado, corresponden a la denominada narrativa de lo inusual; por el otro, son relatos o novelas cortas; finalmente, en ellas suele emplearse un tono poético en la narración. ${ }^{3}$

En su ensayo fundacional "El delito del cuerpo. De la evidencia del cuerpo al cuerpo en evidencia", la estudiosa catalana Meri Torras ha hecho un recorrido histórico-cultural sobre algunas de las concepciones occidentales en torno al cuerpo. A partir de trabajos como el de Torras, se hace patente que la corporalidad es una serie de discursos, imaginarios y normativas construidos a partir de la mirada masculina. Una mirada que ha privilegiado, ante todo, la condición de lo masculinoheterosexual, lo blanco-europeo, lo burgués, etc. Torras señala:

El cuerpo ya no puede ser pensado como una materialidad previa e informe, ajena a la cultura y a sus códigos. No existe más allá o más acá del discurso, del poder del discurso y del discurso del poder. El cuerpo es la representación del cuerpo, el cuerpo tiene una existencia performativa dentro de los marcos culturales (con sus códigos) que lo hacen visible. Más que tener un cuerpo o ser un cuerpo, nos convertimos en un cuerpo y lo negociamos, en un proceso entrecruzado con nuestro devenir sujetos, esto es individuos, ciertamente, pero dentro de unas coordenadas que nos hacen identificables, reconocibles, a la vez que nos sujetan a sus determinaciones de ser, estar, parecer o devenir. (2007: 20)

El objetivo de este artículo es proponer una lectura de la novela breve Moho (2010) de la escritora mexicana Paulette Jonguitud Acosta. Si el humanismo se encuentra en un periodo de crisis, a partir de las teorizaciones posthumanistas se ha podido iniciar la deconstrucción de un conjunto muy amplio de ideas, proyecciones y jerarquías de civilización y progreso. Y uno de los signos más notables de esa crisis del humanismo occidental es el cuestionamiento de las gramáticas binarias, esencialistas y preculturales acerca del cuerpo. En este sentido, la metamorfosis del cuerpo de Constanza, protagonista de la obra, permite el despliegue de una serie de (y una meditación sobre) otras posibilidades corporales: animal, monstruo, vegetal, etc.

Paulette Jonguitud Acosta nació en la Ciudad de México en 1978. Con Moho, obtuvo una Mención Honorífica en el Premio Juan Rulfo de Primera Novela, en 2009. Fue traducida al inglés y publicada en el Reino Unido en 2016. De ese mismo año es el libro de cuentos Son necios, los fantasmas, y de 2017 la novela Algunas margaritas y sus fantasmas. Jonguitud Acosta fue artista residente en la MacDowell Colony y becaria de la Fundación para las Letras Mexicanas y del Fondo Nacional para la Cultura y las Artes, en su programa de Jóvenes Creadores.

\footnotetext{
${ }^{3}$ Carmen Alemany Bay es una de las pioneras en el estudio de las narrativas de lo inusual (2016a, 2016b, 2019). La propia Alemany Bay coordinó con Cecilia Eudave el volumen VIII/1 (2020) de Brumal. Revista de Investigación sobre lo Fantástico (https://revistes.uab.cat/brumal/index). En este, hay artículos muy iluminadores sobre la temática, así como referencias bibliográficas para iniciarse en el estudio de esa modalidad de lo fantástico. Por otro lado, GarcíaValero escribe pertinentemente: "Cuando Carmen Alemany Bay propone la conveniencia de estudiar a una serie de autoras actuales latinoamericanas bajo la denominación de lo inusual, detecta como rasgo de esta modalidad narrativa un sugerente lirismo, las visitas a lo poético y la abundancia de tropos [...]. Estos fragmentos ampliamente líricos acercan el género a los lindes de la prosa poética. Acierta Alemany Bay al entender que el formato breve de estas novelas, que normalmente excede en poco las cien páginas, favorece el aliento poético [...]” (2020: 23).
} 
En Moho se relatan veinticuatro horas en la vida de una mujer madura, Constanza. El punto de partida anecdótico se da a partir de que Constanza descubre que Felipe, su esposo, le ha sido infiel con su sobrina, quien también se llama Constanza. Y con ese descubrimiento, y como una especie de somatización de la infidelidad, a Constanza-tía le brota un pequeño lunar de moho en la ingle. Las siguientes horas son el lapso en el cual se realizan los preparativos para la boda de su hija Agustina y, simultáneamente, cuando se produce su paulatino devenir vegetal.

Desde su publicación, Moho ha llamado la atención de la crítica. ${ }^{4}$ Por mi parte, me propongo hacer una lectura del volumen como un recorrido puntual y una extraordinaria reflexión acerca de lo corpóreo: cuerpos jóvenes y seductores y cuerpos maduros; cuerpos maternos y cuerpos de infantes y de nonatos; cuerpos animales y cuerpos monstruosos. Dedicaré las siguientes páginas a presentar los problemas que implican algunas de esas corporalidades en la novela. Para el análisis se empleará, fundamentalmente, la noción de pensamiento del cuerpo desarrollada por Julieta Yelin.

\section{Sobre el pensamiento del cuerpo}

En "La voz de nadie. Sobre el pensamiento del cuerpo en la literatura latinoamericana reciente", Julieta Yelin se interesa en examinar un corpus narrativo donde "el cuerpo constituye el nexo que articula escritura y vida" (2019: 98). Se trata de obras como Impuesto a la carne de Diamela Eltit, El animal sobre la piedra de Daniela Tarazona, La débil mental de Ariana Harwicz, De gados e homens de Ana Paula Maia, entre otras. Historias en las cuales, "para escribir la vida, se podría decir, es necesario poner el cuerpo; y esto implica no solo tematizarlo, examinarlo, interrogarlo, sino también hacerlo actuar, pensar, imaginar, producir sentido y sinsentido en la escritura" (Yelin, 2019: 98). Para la aproximación a este tipo de literatura, se vale de lo que, provisionalmente, denomina pensamiento del cuerpo. Una conceptualización que debe entenderse, al menos, en dos sentidos complementarios: el que nace del cuerpo pensante y el que se produce a partir de una reflexión crítica acerca de este.

En tanto que uno de los síntomas más visibles de la crisis del humanismo moderno es la desestabilización de la dicotomía irreconciliable bios/zoé (humano/animal; cultura/naturaleza; racional/instintivo; cuerpos significativos/cuerpos insignificantes), diversos materiales de la literatura latinoamericana son susceptibles de ser leídos, justamente, en la zona donde se exhiben esos límites, fisuras y entrecruces biopolíticos (Giorgi, 2014: 11-41). Manifestaciones de este territorio fluctuante y problemático son los relatos donde se ponen en acción cuerpos calificados como aún-no-humanos o ya-no-humanos, cuerpos inhumanos o infrahumanos: cuerpos enfermos, enajenados, animalizados, monstruosos, metamorfoseados, desindividualizados, putrefactos, etc.

\footnotetext{
${ }^{4}$ López Morales (2014), por ejemplo, ha estudiado el fenómeno de la metamorfosis de Constanza. Loría Araujo (2019) ha analizado las connotaciones de la "infección" micótica en esta novela, así como en los relatos "Isla cuerpo adentro" de Cecilia Eudave y en "Hongos" de Guadalupe Nettel. Ruiz Pérez (2018) se ha detenido en lo que denomina "matrofobia" en la obra de Jonguitud Acosta, así como en Bestiaria vida de Cecilia Eudave y en El animal sobre la piedra de Daniela Tarazona. La propia Ruiz Pérez (2020) ha examinado las manifestaciones psicoanalíticas del "Yopiel" (Anzieu) y del cuerpo (Nancy y Butler) en el texto.
} 
Para la lectura de esos documentos, donde lo corpóreo se muestra en lo fundamental como un devenir permanente, Yelin enmarca el pensamiento del cuerpo en el concepto más amplio de la denominada lectura biopoética. Esta sería

aquella que hace lugar, o que produce, un pensamiento del cuerpo, permitiendo, así, la observación de lo humano como proceso, es decir, la percepción de subjetividades todavía-no-humanas. El pensamiento del cuerpo podría ser entendido, desde este punto de vista, como una vía de aproximación a la forma-de-vida, una exploración de los procesos mediante los cuales los humanos están continuamente autoafirmándose. La labor del escritor y del crítico se conciben, en este marco, como prácticas generadoras de las condiciones para que el pensamiento del cuerpo tenga lugar, para que la vida (se) piense por sí misma. (Yelin, 2019: 101)

Moho es una novela sobre encuentros, disputas y transformaciones de los cuerpos. La primera de esas confrontaciones encara a las dos Constanzas, a partir de la infidelidad de Felipe con su sobrina. ${ }^{5} \mathrm{Y}$ las enfrenta inicialmente con base en modelos sociales-sexuales tradicionales. Desde luego, no es casual que la diégesis de la novela comience veinticuatro horas antes de la boda de Agustina: el matrimonio funcionaría aquí como la posibilidad de la confirmación/continuación del modelo familiar y de pareja dictado por la normatividad social masculina. Así, tendríamos por un lado a la tía, censurándose en las primeras páginas porque su cuerpo maduro no cumple ya con las expectativas eróticas impuestas: "Entré al baño [dice la protagonista] y me desnudé frente al espejo; no hallé en mi imagen a la mujer joven que siempre imagino al pensar en mí. Examiné mi cuerpo, audición personal que reprobaba día tras día. Cascada de adjetivos: pies grandes, tobillos sombreados por las várices, muslos y cadera anchos, vientre vasto, senos amedrentados" (12). En contraste, se tiene la descripción de la joven hecha por su tía:

Con el pretexto de entrar en la regadera, [Constanza-sobrina] comenzó a desnudarse [frente a mí]. Yo: callada para elegir muy bien cada palabra y no volver a ser tomada por sorpresa. Se quitó el sostén, sus senos pesados cayeron unos centímetros sobre el vientre. [...] Sentí que ella habitaba hasta el último rincón de su cuerpo, ningún espacio le era ajeno, ni una uña del pie, ni medio talón o el lóbulo de una oreja: todo estaba ocupado, colonizado. Le gustaba su cuerpo y la envidié. (19)

Constanza contra Constanza. ${ }^{6}$ En este sentido, se vuelve muy significativo el motivo reiterado del espejo en la novela. Al comienzo de la narración, el azogue funciona como un espacio donde se manifiesta constantemente, fantasmalmente, la sobrina que disputa la posesión del varón (y que, al repetir el nombre de su tía, es de alguna manera un espejo de ella). ${ }^{7}$ De esta manera, el

\footnotetext{
${ }^{5}$ En un primer momento, el pequeño lunar de moho en la ingle de Constanza sería, acaso, una somatización de la traición: es la herida que ha infligido la pareja infiel: "Entré en la regadera, bajo el chorro de agua hirviendo; tallé, froté, arañé, la mancha no cedió. Volví frente al espejo y me vacié encima cuanto producto de limpieza pude hallar. Nada. Luego ataqué con la lima metálica de un cortaúñas, pero la piel se irritó sin que la mancha cediera. La punta de la lima me hizo un pequeño corte. Sangre con fondo verde" (Jonguitud Acosta, 2010: 12). En adelante, cuando cite de la novela, anotaré solo la(s) página(s) referidas entre paréntesis.

${ }^{6}$ La tía comenta, por ejemplo, sobre el exhibicionismo obsceno su sobrina: "Quería mis ojos pegados a ella, se desnudaba para mí, para mostrarme el terreno donde había ganado su mejor batalla" (20).

${ }^{7}$ En las primeras páginas, los espejos son una especie de pantallas de proyección de la traición: "Ya había caído en esa trampa, ya me había parado a ver esos espejos y a escuchar su historia. Cuando Felipe admitió lo que había pasado,
} 
espejo no solo sería aquí un cristal para posar la mirada en nuestra apariencia, sino, sobre todo, un instrumento que condensa y donde se localiza la mirada social de los otros, una herramienta para evaluar si se están cumpliendo los imaginarios corporales que recibimos día con día. Quizás por ello, conforme Constanza-tía va aceptando su devenir vegetal y sacudiéndose el lastre de las expectativas heteronormativas, también se va desvaneciendo el espejo como emblema dentro de la narración: "Hace ya un buen rato que no me paro frente al espejo" (51).

\section{Cuerpos animalizados, cuerpos monstruosos}

Yelin recuerda las intervenciones de Daniel Link en torno al "giro autobiográfico", presente en la literatura actual. Para ella, en un número importante de obras contemporáneas, más que un impulso autobiográfico, habría un giro "auto-zoográfico", esto es, "la búsqueda de una experiencia de sí en las afecciones - en el sentido de afecto, apego o inclinación, pero también en el de alteración y padecimiento - de la vida corporal" (Yelin, 2019: 102). Por supuesto, hay momentos de Moho que podemos leer desde esa perspectiva de la alteración y del padecimiento. Es decir, desde claves de lo patologizante.

Loría Araujo, quien estudia Moho y otras narraciones mexicanas con base en la idea de la infección, señala: "Los personajes leídos como infectados experimentan tres fases principales: en principio, el extrañamiento ante el descubrimiento de su infección; más adelante, la patologización o lectura negativa de su condición; y por último, una resignificación, sea esta leída como liberadora o legitimadora del poder sobre sus cuerpos" (2019: 177). Si bien la evolución de Constanza no atraviesa de manera lineal e inequívoca por esas tres etapas, es cierto que hay momentos muy claros de autovaloración patologizante. Cuando la protagonista percibe que el hongo está creciendo en su ingle, navega en Internet para consultar manuales dermatológicos. Lo que descubre en las imágenes de la web es un verdadero museo de lo teratológico: "Nunca imaginé que la piel abrigase tantos horrores: marcas negras derretían los miembros de un anciano; hongos quemaban extremidades, consumían dedos, transformaban el brazo de un hombre en una extensión que sólo pude definir como una rama" (23).

El corpus literario que le interesa a Yelin, así, está caracterizado por narraciones donde, lejos de enfatizar lo corporal como modelo de lo homogéneo, lo unitario y la plenitud vital, nos hallamos en un terreno de vacilaciones identitarias. Y la novela de Jonguitud Acosta sería parte de ese

conjunto de ficciones $[\ldots]$ en las que el foco no está puesto sobre la experiencia íntima de un yo sino, de modo más oblicuo o distante, sobre la ambigüedad de la relación entre vida biológica y

subí a esconderme al estudio, a que se me enfriara el cuerpo, a contener la rabia para no quedarme tumbada como mi padre en una cama y sin poder ni ir al baño sola. Pero una vez en el estudio los espejos se convirtieron en cuadros delatores: vi a mi sobrina contoneándose risueña y al hombre detrás, extasiado. ¿Qué pasó aquí? El reflejo de la joven se rio mientras contaba lo que yo ya sabía: fue a recoger un vestido que le hice para una fiesta pero quiso medirse otros y Felipe se ofreció a ayudarle a elegir. Estaban solos. Ella se probó varios mientras él la veía sentado entre los maniquíes. «Sentado aquí», dijo el reflejo de Felipe, palmas sudorosas. Y el reflejo de Constanza contó que se subía el vestido y preguntaba: «¿Así o más corto?»” (22-23). 
vida personal. Son textos en los que la incertidumbre no contamina los movimientos del yo, sino en los que directamente cuestiona su posibilidad de constitución, algunas veces recurriendo a formas de lo inhumano — el animal, el monstruo, el espectro_-, otras tocando zonas en las que se puede apreciar la distancia entre lo humano y el lenguaje - la infancia, la locura, la experiencia de las drogas, la agonía-. (Yelin, 2019: 103)

Si leemos Moho como un texto de la ambigüedad corporal y de múltiples posibilidades de conformación para esta, se comprende que el cuerpo sea valorado desde ópticas donde parece superponerse lo infantil, lo patológico, lo animal y lo monstruoso. Y esa promiscuidad pone en crisis, en principio, la visión del cuerpo como depositario de la identidad de la propia protagonista. Mientras observa extasiada el manual dermatológico, comenta:

Hallé, luego, a un niño cubierto por escamas; tenía la espalda como si tras sumergirlo en lodo le hubiesen puesto a secar al sol: barro cuarteado con delgadas carreteras de piel sana entre el desierto de costras. Se me helaron las piernas; el engendro me miraba, un duende, una cría de dragón, ojos alargados hacia atrás, cabello a media coronilla, cara cubierta por escamas terrosas. Escamas. Verdes. Como mi mancha, como yo. ¿Su problema habrá iniciado lentamente, como el mío? O tal vez despertó así una mañana, convertido durante el sueño en ¿qué? No es un niño, es otra cosa. ¿Dejaré yo de ser mujer? ¿Se me descompondrá el cuerpo? ¿Se me caerá algo? (25)

Para Braidotti, el ente "posthumano" es un ser con una "subjetividad post-identitaria, nounitaria y transversal, basada en relaciones con otros humanos y no-humanos" (citado por Valera y Alvarado Marambio, 2019: 312). Por su parte, Yelin insiste en que:

Por eso no hay en los textos [estudiados] una exacerbación de lo corporal como unidad o plenitud vital; por el contrario, el procedimiento consiste en poner en entredicho la existencia de un cuerpo homogéneo, identificable, es decir, de un organismo. Esa desintegración permite que en ocasiones se perciba la emergencia de una vitalidad que no se puede asignar a ningún viviente; eso sucede cada vez que una voz no atina a decir yo, cada vez que una descripción corporal pierde de vista la especificidad humana, cada vez que un diálogo se funde con el continuo del relato, desenfocando al sujeto de la enunciación, cada vez, en fin, que la prosa se flexiona para que allí emerja un cuerpo desorganizado, despersonalizado, un cuerpo pensante. (Yelin, 2019: 106)

Durante su devenir vegetal, podemos identificar algunos momentos en los cuales se percibe que Constanza es consciente de la disolución de su especificidad humana. Son instantes que solo parecen explicarse a partir de una especie de involución que el moho habría echado a andar y que tendrá como consecuencia el borramiento definitivo de las huellas de lo que (re)conocemos como identidad, dando lugar a lo orgánico como manifestación biológica en toda su potencialidad vital: "mi moho es térmico, los filamentos cerrados se humedecen pero filtran el aire, el agua, el dolor; piernas precámbricas, ejemplares de las primeras formas de vida, aún indecisas entre ser animal o 
planta, llenas de posibilidades. Era ya medio monstruo, media mujer, un demonio o un dios, quizá una criatura fantástica" $(54){ }^{8}$

Como una consecuencia de la desestabilización del cuerpo como entidad biológica - $\mathrm{O}$ corriendo de manera paralela a esa desestabilización-, se produce una significativa exacerbación de la voz narrativa en Moho. Yelin lo explicaría, acaso, de la siguiente manera: "Ya no se escribe la vida, sino que es una vida la que escribe" (Yelin, 2019: 110). Y abunda al respecto:

Los diálogos también son incorporados en ese espacio intersticial que no pertenece íntegramente a la conciencia, ni tampoco al mundo. El diálogo, como el cuerpo, está en medio, anulando el vacío, la distancia que se abre entre los hablantes cada vez que una voz toma cuerpo. Esa continuidad entre ruido y habla, entre diálogo y narración, entre segunda y tercera persona, tiene lugar, evidentemente, en la prosa, pero se origina en una transformación del punto de vista de la escritura o, para decirlo con mayor precisión, en una modificación del vínculo entre escritura y vida. (Yelin, 2019: 110)

Creo que la gran cantidad de interrogantes lanzadas por Constanza en algunos pasajes serían un reflejo de esa auto-zoografía como alteración y padecimiento, de ese cuerpo-vida escribiendose - (d)escribiendo-se — desde los intersticios permeables de la dualidad bios/zoé:

¿Era yo la plaga? Mujer de piel verde y alas negras, hoz entre las manos y cola de dragón que se sacude de un lado a otro barriendo a su paso a todos los residentes del pueblo: cuerpos rotos en los umbrales, madres que intentan proteger a sus hijos tras brazos inútiles, viejos derrumbados contra las paredes, buitres sobrevolando el futuro festín.

¿La aniquilación era por mi causa? Era yo quien presentaba las marcas del horror, sólo me faltaban las cuencas oculares vacías y la cola larga.

¿Quién era el monstruo?

¿Quién la bestia?

¿Quién la infección? (32-33) ${ }^{9}$

\footnotetext{
${ }^{8}$ Marchesini afirma: "En la concepción posthumanista, entonces, lo humano no es más la emanación o la expresión del hombre, sino el resultado de la hibridación del hombre con las alteridades no-humanas. Esto significa que lo humano excede las características del hombre" (citado por Valera-Alvarado Marambio, 2019: 313).

${ }^{9}$ Un acercamiento muy sugerente a los imaginarios de lo monstruoso - expresión paradigmática de la síntesis de lo humano con alteridades no-humanas (animales, tecno-científicas...) - en el contexto posthumanista es el de Valera y Alvarado Marambio (2019). Al tratarse Moho de un texto literario, todo planteamiento de la "monstruosidad" de Constanza se mantiene en los márgenes de la ficción. Sin embargo, a partir de los avances científicos y tecnológicos, la posibilidad de lo monstruoso como híbrido de lo humano y lo no-humano (orgánico e inorgánico) está generando toda una serie de debates éticos, políticos y filosóficos. Comentan Varela y Alvarado Marambio: "El programa posthumanista de difuminación de límites y bordes parece un programa para el advenimiento de lo monstruoso. Es curioso constatar que los teóricos post-humanistas han estado conscientes de ello. Lestel, en especial, ha sido un teórico que ha puesto de relieve estas conexiones. La cercanía del posthumanismo con esta tradición, lejos de ser un motivo para distanciarse de las connotaciones más preocupantes del programa ético-político posthumanista son para Lestel un motivo para abrazar la idea de lo monstruoso como algo bienvenido: «Amamos los monstruos no sólo por el hecho de que somos monstruos darwinianos, sino también porque la monstruosidad es nuestro futuro y porque nosotros estamos simplemente condenados a amar a los monstruos» [...]" (2019: 316).
} 


\section{Cuerpos maternos, cuerpos infantiles}

Tradicionalmente, se le ha asignado a la maternidad el grado máximo de plenitud de la corporalidad femenina. ${ }^{10}$ En este ámbito, Moho es una narración de una ambigüedad muy llamativa. Ruiz Pérez ha examinado esta y otras novelas breves desde la perspectiva de lo que denomina matrofobia. A saber:

La matrofobia se puede considerar la escisión femenina del yo, el deseo de expiar de una vez por todas la esclavitud de nuestras madres, y convertirnos en seres libres. La madre representa a la víctima que hay en nosotras, a la mujer sin libertad, a la mártir. Nuestras personalidades parecen marcharse y superponerse peligrosamente a la de nuestra madre. En el intento desesperado de conocer dónde termina la madre y empieza la hija, optamos por la extrema solución quirúrgica. (Rich citada por Ruiz Pérez, 2018: 4)

A consecuencia de lo anterior, se produciría, "por tanto, un sentimiento de repulsa hacia la figura materna incentivado por lo que la madre representa en el sistema heteropatriarcal: resignación y acatamiento de la sumisión, es decir, la madre ha aceptado y asimilado una actitud pasiva en la sociedad" (Ruiz Pérez, 2018: 4). La novela de Jonguitud Acosta está llena de madres deficientes. Constanza-tía tuvo que adoptar a Constanza-sobrina, abandonada por su madre Hortensia. Constanza-tía tampoco recibió los mejores cuidados en la infancia ("Cuando aún vivía mi padre, mamá no se ocupaba de nada. Nunca preguntaba si los niños habíamos comido, si hacíamos la tarea. Nada" [13]). Por otro lado, la rama mayor del árbol genealógico, la abuela Loreto, fue una mujer abrumada por dos obsesiones: la migraña y la quiromancia (nótese la manera en que elementos de lo corpóreo marcaron a esa mujer: la enfermedad y las líneas de su mano como un fatum al parecer irrevocable).

Desde mi perspectiva, frente a esa matrofobia, podemos observar como aspecto complementario un sentimiento de filicidio presente en Moho. Ya en la exploración del catálogo de enfermedades epidérmicas vemos parte de los sentimientos de rechazo a la maternidad por parte de Constanza-tía: "Me hipnotizó la foto de un pequeño en una incubadora: ojos cerrados por formaciones parecidas al coral. ¿Qué habrá sentido su madre cuando lo expulsó del vientre? ¿Alivio? Pero todas las madres lo sienten; ¿decepción, entonces, porque no estuviese muerto? ¿Habría un poco de eso, también, en todas las madres?” (24). De esta manera, se subraya que el amor filial no es necesariamente el primero de los sentimientos de algunas mujeres. Con mayor razón, si el producto naciera contrahecho: "En otro tiempo, las madres elevaban sus plegarias a los dioses familiares para solicitar un cachorro humano. Muchos híbridos se desmembraron contra los dientes de un despeñadero; otros respiraron su primer aliento para, segundos después, exhalar el último sofocados bajo unas mantas" (52). No es casual que una de las figuras aludidas al principio de la novela sea Lady Macbeth: la mujer sin hijos; la mujer que, si los tuviera, estaría dispuesta a asesinarlos en su búsqueda del poder.

${ }^{10}$ Véase, inicialmente, Lagarde y de los Ríos (2005: 363-459). 
De acuerdo con Giorgi, los fundamentos de la biopolítica foucaultiana han permitido discernir el complejo límite entre bios y zoé. Es decir,

entre las vidas a proteger, a cuidar, a "futurizar" — esto es: cuáles son, para usar las palabras de Foucault, los cuerpos que se "hacen vivir": dónde se aplica el "hacer vivir" de una sociedad- y cuáles son los cuerpos y las vidas que se abandonan, que se reservan para la explotación, para la cosificación, o directamente para el abandono o la eliminación (de nuevo, para volver a Foucault: los cuerpos que son "empujados hacia la muerte"). (Giorgi, 2014: 15)

En el pasaje recién citado de Moho parece insinuarse que la primera persona en ejercer una serie de decisiones biopolíticas es la madre. En este sentido, tal vez pueda afirmarse que detrás de un aborto también habría una acción biopolítica de la mujer: una especie de biopolítica doméstica. En otro lugar de la novela, se lee: "Constanza nunca fue un bebé [comenta la tía sobre su sobrina], al menos no para mí. No la llevé en mi cuerpo, no tuve sobre ella el poder de todas las madres, que es el de la muerte" (62).

Constanza-sobrina es madre de dos hijos. Pero quien ocupa el centro del relato es el niño que abortó veinte años antes, auxiliada por su tía. Y es Constanza-tía quien, durante su devenir vegetal, constantemente alucina con el fantasma del embrión expulsado. En una escena estrujante, y durante una de sus apariciones, Constanza-tía toma el cuerpecito de Rafael (o, más bien, su imagen espectral) y reitera su decisión de interrumpir el embarazo, de apoyar el filicidio: "Torné el cuello del feto entre índice y pulgar, abrí la boca y metí su cabeza entre mis labios; sentí los dientes rozar su espalda. Mordí, y cuando esperaba escuchar su cráneo romperse como cáscara de huevo, mis dientes se hundieron en plastilina" (45). Eso que muerde es, en realidad, la plastilina que usó Constanza-sobrina durante su infancia para fabricar un cenicero como regalo escolar.

De acuerdo con Yelin, en el corpus que analiza, las escritoras despliegan dramáticos procedimientos de de-subjetivación. Con ello, "vivencian [...] la imposibilidad del reconocimiento, es decir, el derrumbe de la ilusión de correspondencia entre el yo y el mundo. En efecto, las cuatro [autoras] desnudan la inexistencia de una identidad que trascienda lo sensorial; ven y se ven con el ojo del cuerpo, una lente que abre el mundo como proceso de continua recreación" (Yelin, 2019: 111). Una de las manifestaciones más notables de ese énfasis en la de-subjetivación y en la presentación de un universo deviniente es la aparición recurrente de cuerpos preñados y/o nonatos: "cuerpos en estado de gestación — gestantes o gestados — : la imagen de la vida produciendo nueva vida" (Yelin, 2019: 111). Esto explicaría, en parte, la presencia obsesiva del embrión Rafael. Aclararía las imágenes de Rafael abriendo los párpados al final de la novela para conocer el mundo (para re-conocer-se en el mundo). Mirada de la de-subjetivación más pura: "Rafael ha abierto un ojo. No mucho, una rendija. Mueve el ojo" (86). Y aclararía el porqué se coloca entre las piernas vegetales de Constanza-tía en el último —y muy ambiguo - capítulo del libro ("Rafael. Sé tu nombre. Rafael entre mis piernas" [86]): vendría a ser una estampa que simboliza la continuidad del proceso de gestación que, aunque interrumpido veinte años atrás, ya no podrá detenerse. O que, acaso, nunca se habría detenido.

Si los textos estudiados por Yelin están caracterizados por un fenómeno de desubjetivación, también puede decirse que en ellos encontramos "un discurso inasignable [que] 
discurre acerca de la inefabilidad del entorno" (Yelin, 2019: 111). De esta manera, en esas narraciones "nadie habla. Nadie dice algo" (Yelin, 2019: 111; las cursivas son de Yelin). En un pasaje, Constanza-tía le dice de manera significativa a un "niño-cocodrilo": "No somos dos, no somos nada. Yo no soy nada contigo" (25).

Moho es un fascinante catálogo de referencias a la corporalidad animal: desde los recuerdos infantiles de Constanza-tía cuando revisaba libros de zoología para gozar de las imágenes de burros y cerdos durante la cópula, hasta la atracción por la zoología fantástica de El Bosco y El jardín de las delicias, pasando por la metamorfosis, que para la mujer implica un camino hacia la animalización. Y tenemos que esa corporalidad es significativa por lo que el animal representa en contraste con lo humano como "otredad radical". Un amplio número de nuestras (pre)concepciones sobre lo animal han estado dictadas por la noción y la convicción de la carencia: la falta de alma, la falta de racionalidad, la falta de lenguaje, etc. Del mismo modo, por dicotomías de lo humano/animal marcadas por el maniqueísmo: cultura/naturaleza; racional/instintivo; espiritualidad/corporalidad. Por otro lado, Gabriel Giorgi comenta que no todo cuerpo o vida humana se corresponde con una persona. Frente a la noción jurídica y religiosa de persona tenemos un amplio arco de opciones, cuya corporalidad se ha clasificado como de las aún-no-personas a las ya-no-personas (niños, enfermos, dementes, anormales, migrantes ilegales). O, como dice Giorgi: "persona plena será aquella que tiene control sobre su propio cuerpo, quien se declara «dueña» de su cuerpo y capaz de someter y de conducir su «parte animal»" (2014: 24).

Sin embargo, en obras como Moho, donde se da una fractura de las distinciones entre bios y zoé, Yelin explica que "mediante la producción de cuerpos pensantes, en el mismo sentido se puede leer la insistencia en el borramiento de la frontera entre logos y phoné: el grito que puede volverse palabra para deshacerse nuevamente" (Yelin, 2019: 107). La risa —ese resto de la voz humana, que se mezcla de manera inquietante con los límites del sonido animal - es lo que atestiguamos en este pasaje: "La risa [relata Constanza-tía] me surgió de algún sitio entre el estómago y el pecho. Me estremecí al intentar tomar aire, y cuando al fin los pulmones consiguieron llenarse, se me salió un chillido seguido por una carcajada que se me desbordó entre los dientes" (45).

\section{Consideraciones finales}

La novela de Paulette Jonguitud Acosta es una obra extraordinaria y de una profunda ambigüedad. Ambigüedad que, como hemos visto, caracteriza a los cuerpos en el texto; pero que, seguramente, se refleja también en el cuerpo del texto.

El capítulo Dieciséis de la novela es paradigmático, digamos, de esa ambivalencia. En principio, Constanza parece rechazar decididamente las normativas heteropatriarcales: "Criaturas extrañas somos todos. La belleza está en la diferencia. ¿Quién establece los parámetros de lo hermoso? Hasta el cansancio había escuchado, y repetido, estas y muchas frases semejantes, como si fueran parte de un paquete de valores que se entregara a los padres al nacer su primer hijo" (52). Asimismo, la vemos adherirse a una visión posthumanista durante su devenir vegetal: "Si no se le 
comparaba con un cuerpo humano [se refiere a su propia anatomía en proceso de transformación], podría incluso ser algo bello" (52).

Desestabilización corpórea, de-subjetivación, disolución identitaria. El potencial de la vida y la vida en todo su potencial orgánico. Ya hemos atestiguado escenas donde la difuminación o la permeabilidad de las categorías bios-zoé llevan a una oscilación de imágenes entre la evolución y la involución:

Somos, siseé junto con el niño-cocodrilo. Cada uno de esos cuerpos era una creación diferente, cada llaga semejante a una sanguijuela, cada mancha con forma de nube o de hongo, todo eso podía ser un viaje, un cambio, una evolución. [...] Constelaciones de lunares rojos, una niña con la espalda cubierta por manchas de leopardo, una mujer con el rostro derretido, un joven con burbujas de piel en todo el cuerpo, arena de playa en las axilas; todo señal de algo, un salto adelante o atrás, tal vez reminiscencia de criaturas desaparecidas [...] (53)

La conclusión de Constanza al respecto parece ser el corolario de un manifiesto posthumanista alentador: "El moho no tenía que ser una prisión. Podría ser una salida" (53). La novela concluye con la (des)integración de Constanza-tía, Constanza-sobrina y el fantasma de Rafael al ciclo biológico de la naturaleza. No obstante, también con la celebración por los esponsales de Agustina, con lo que parece confirmarse y dársele continuidad al modelo familiar y de pareja que se cuestiona constantemente a lo largo de la obra. ¿Cómo debemos interpretar esa escena final? Justamente, una de las mayores virtudes de Moho de Paulette Jonguitud Acosta tal vez sea no clausurar de manera definitiva y en un sentido unívoco la interpretación de su novela.

\section{Bibliografía}

ALEMANY BAY, Carmen (2016a): "Bestiaria vida, de Cecilia Eudave: novela corta, novela de laberintos, novela de lo inusual". Revista de Literatura Mexicana Contemporánea, XXIII/68: 103-118.

--- (2016b): "Narrar lo inusual. Bestiaria vida de Cecilia Eudave y El animal sobre la piedra de Daniela Tarazona". Romance Notes, LVI/1: 131-141. DOI: https://muse.jhu.edu/article/620146.

--- (2019): “¿Una nueva modalidad de lo insólito en tiempos posmodernos? La narrativa de lo inusual". En Natalia Álvarez Méndez y Ana Abello Verano (coords.): Realidades fracturadas. Estéticas de lo insólito en la narrativa en lengua española (1980-2018). Madrid, Visor: 307-324.

CRAGNOLINI, Mónica (2014): "Extraños animales: La presencia de la cuestión animal en el pensamiento contemporáneo". Revista Latinoamericana de Estudios Críticos Animales, 2: $15-33$.

GARCÍA-VALERO, Benito (2020): "Los trazos en el cuerpo, el cuerpo a trazos. Imaginario, lirismo y alteridad interior en la narrativa de lo inusual escrita por mujeres". Brumal. Revista de Investigación sobre lo Fantástico, VIII/1: 17-34. DOI: https://doi.org/10.5565/rev/brumal.646. 
GIORGI, Gabriel (2014): Formas comunes. Animalidad, cultura, biopolitica. Buenos Aires, Eterna Cadencia.

JONGUITUD ACOSTA, Paulette (2010): Moho. México, Fondo Editorial Tierra Adentro.

LAGARDE Y DE LOS RÍOS, Marcela (2005): Los cautiverios de las mujeres. Madresposas, monjas, putas, presas y locas. México, UNAM.

LÓPEZ MORALES, Laura (2014): "Bitácora de una metamorfosis. Moho, de Paulette Jonguitud Acosta”. Romance Notes, 54: 93-103. DOI: 10.1353/rmc.2014.0076.

LORÍA ARAUJO, David (2019): "Hacia otra piel: Del cuerpo «infectado» al devenir corporal en Cecilia Eudave, Paulette Jonguitud y Guadalupe Nettel". En Mónica Quijano Velasco et al. (eds.): Literaturas en México (1990-2018). Poéticas e intervenciones. México, UNAM: 161-181.

RUIZ PÉREZ, Nieves (2018): Las madres enemigas en la narrativa de lo inusual. Análisis de la matrofobia en tres novelas mexicanas. Tesis de Maestría. Alicante, Universidad de Alicante.

--- (2020): "La metamorfosis del «Yo-piel» y el cuerpo vacío/invadido a través de la narrativa de lo inusual en Moho, de Paulette Jonguitud Acosta". Brumal. Revista de Investigación sobre lo Fantástico, VIII/1: 49-69. DOI: https://doi.org/10.5565/rev/brumal.651.

TORRAS, Meri (2007): "El delito del cuerpo. De la evidencia del cuerpo al cuerpo en evidencia". En Meri Torras (coord.): Cuerpo e identidad I. Estudios de género y sexualidad I. Barcelona, Universitat Autónoma de Barcelona: 11-36.

VALERA, Luca-José Tomás ALVARADO MARAMBIO (2019): "Posthumanismo e hibridación". Pensamiento. Revista de Investigación e Información Filosófica, LXXV/283: 307-319. DOI: https://doi.org/10.14422/pen.v75.i283.y2019.016.

YELIN, Julieta (2017): "Breve estado de la cuestión animal". Perífrasis. Revista de Literatura, Teoría y Crítica, VIII/15: 29-43. DOI: https://doi.org/10.25025/perifrasis201781502.

--- (2019): "La voz de nadie. Sobre el pensamiento del cuerpo en la literatura latinoamericana reciente". Pasavento. Revista de Estudios Hispánicos, VII/1: 97-113.

(C) Daniel Zavala Medina

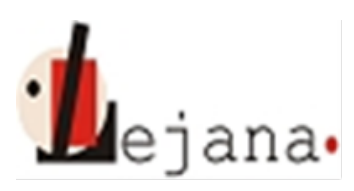

http://ojs.elte.hu/index.php/lejana

Universidad Eötvös Loránd, Departamento de Español, 1088 Budapest, Múzeum krt. 4/C 